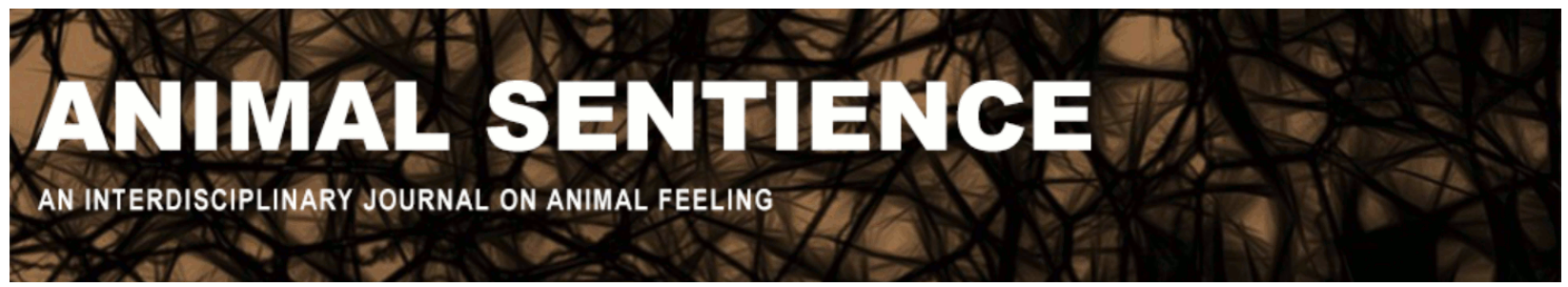

Eilam, David (2017) Animals do not commit suicide but do display behaviors that are precursors of suicide in humans. Animal Sentience 20(7)

DOI: 10.51291/2377-7478.1292

Date of submission: 2018-01-08

Date of acceptance: 2018-01-12

(c)

This article has appeared in the journal Animal

Sentience, a peer-reviewed journal on animal

cognition and feeling. It has been made open access,

free for all, by WellBeing International and deposited

in the WBI Studies Repository. For more information,

please contact

wbisr-info@wellbeingintl.org.

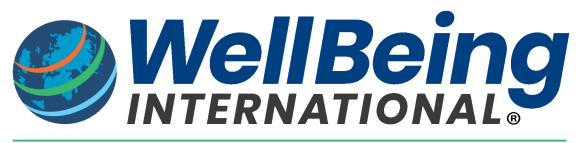

SOLUTIONS FOR PEOPLE, ANIMALS AND ENVIRONMENT 


\title{
Animals do not commit suicide but do display behaviors that are precursors of suicide in humans
}

Commentary on Peña-Guzmán on Animal Suicide

\author{
David Eilam \\ School of Zoology \\ Tel-Aviv University
}

\begin{abstract}
Although my commentary begins with a report about a monkey committing suicide, I agree with the target article's concluding statement that we cannot currently prove that any animal has committed suicide. The author's proposed continuist approach is based on animal behaviors reminiscent of symptoms preceding suicide in humans (e.g., deep depression and grief). However, in both humans and nonhuman animals, these are just potential precursors of suicide, and dying as a result of grief is not necessarily suicide. In the absence of supporting evidence, the continuist hypothesis of animal suicide is not sustained.
\end{abstract}

David Eilam, Professor of Zoology and Head of the Laboratory for the Analysis of Human and Animal Behavior at Tel-Aviv University, does research on spatial cognition in individuals and groups, compulsive behavior in animals and in OCD patients, and predator-prey interactions. david-eilam.weebly.com/

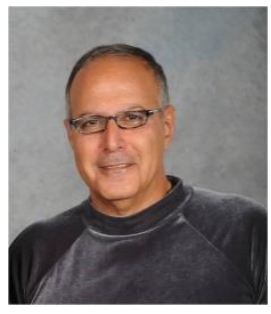

"He is alive for he cannot afford a funeral" (Persian proverb)

The question of whether animals can commit suicide boils down to three possibilities, which by their very mere nature are mutually exclusive: (i) Animals cannot commit suicide; (ii) Animals can and do commit suicide but humans fail to see and understand it as such; and (iii) There is a broader meaning for the term suicide as applied in humans, which in animals includes suicidelike or suicide-precursor behaviors. There is only one description to date of an animal committing suicide in an act that seems to reflect self-awareness and free will but not necessarily an understanding of the finality of death. This case was published in British newspapers in 1932, and described how visitors to a recently-opened zoo witnessed a rhesus monkey putting his head through a noose that it had made from a rope hanging in its cage, and deliberately jumping to its death (Box 1).

To my knowledge, this is the only reported case in which an animal apparently displayed rational preparation for an action that led to its death in a horrible replica of suicide in humans. It is nonetheless possible that this was merely a sequence of unintended activities with an unfortunate ending, and devoid of any explicit awareness of the consequential death. There are other anecdotal descriptions of animals jumping to their death, but these seem to have been more like an automated escape response or reckless risk-taking rather than a rational suicidal 
behavior. For example, when exposed to a snake, the banner-tailed kangaroo rat (Dipodomys spectabilis) spends extended periods within striking distance of the snake, frequently approaching the snake's head in nose-to-snout contact (Randall et al., 1995). While this and other life-risking behaviors of confronting a predator seem like intentional behaviors, they are remote from what might be considered as suicide-like behaviors. As Peña-Guzmán (2017) acknowledges in the conclusion of the target article: "we cannot currently prove that any animal has committed suicide as a matter of fact" (p. 18).

“London, July 14, 1932. Sightseers at the Upton Zoo, Chester, witnessed an apparently deliberate suicide by a monkey. The monkey first gnawed through a six-feet rope hanging in his cage, tied one end to the bough of a tree, made a noose with the other end, inserted his head with great deliberation, pulled the slipknot tight, climbed the tree and jumped. Death was instantaneous. The keeper said that in a lifetime's experience he had not known an animal deliberately commit suicide. He is now guarding the monkeys, which might emulate their companion, thinking they had discovered a new game. The reason of the suicide is unknown. Had he domestic difficulties, or was he tired of life? Shocked spectators, expecting amusement, witnessed the tragedy."

c.f. Monkey Commits Suicide, 1932
}

The possibility that animals can and do commit suicide but that we fail to see and understand it as such cannot be either proved or disproved at present. Animal cognition is still regarded topdown from the heights of human mentality. However, understanding the impact of animal emotions on their behavior requires perceiving the world through an animal's eyes (and perhaps other senses). Our ability to do so is very limited at present, especially in the context of the mental life of animals. From a human viewpoint, suicide becomes a choice against the background of past life experience, or in order to materialize a divine idea and/or future benefit (i.e., the case of suicide bombers). Implicit in this is the implication that suicide in animals too must have a component of mental time-travel (Suddendorf and Corballis, 2007) in the form of emotionally living the past and/or planning the future. Whether such capacities exist in animals is still unclear.

Little scientific evidence is currently available regarding animal suicide-like behaviors (in contrast to the beliefs, hypotheses, and anecdotes that are introduced by Peña-Guzmán, 2017). These are limited to a scrutiny of behavioral patterns in animals that resemble those human behavioral patterns that are usually precursors or progenitors of suicide. These are discussed in the target article as negative emotions and self-destructive behaviors. Indeed, deep depression, seclusion, and anhedonia that ultimately lead to death are commonly described in animals. This understanding perhaps began with Goodall's (1996) description of Flo, the dominant chimpanzee matriarch of the "F" family. When Flo died, her 8-year-old son Flint, who was still dependent on her (i.e., sleeping with her at night, and still riding on her until recently), became lethargic and depressed. Flint hardly ate, and ceased to interact with other chimpanzees. He consequently became sick and died three weeks after Flo's death (Box 2). Flint's behavior meets King's $(2013,2016)$ two criteria for animal grief: long co-habitation before the death of the partner, and major behavioral change after the partner's death. Flint's grief clearly reflects the deep depression caused by the absence of his mother, and he seems to lose the will to live 
without her. However, had Flint understood the finality of the death of his mother? Did he rationally plan to die? Nobody knows.

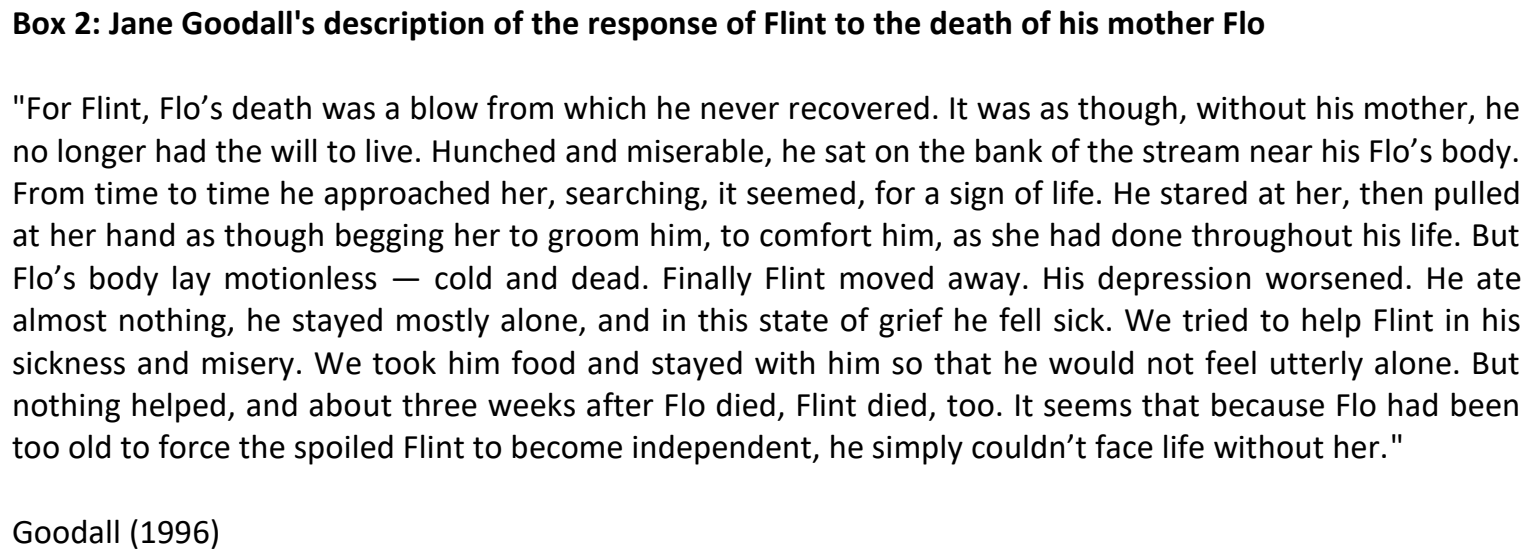
no longer had the will to live. Hunched and miserable, he sat on the bank of the stream near his Flo's body. From time to time he approached her, searching, it seemed, for a sign of life. He stared at her, then pulled at her hand as though begging her to groom him, to comfort him, as she had done throughout his life. But Flo's body lay motionless - cold and dead. Finally Flint moved away. His depression worsened. He ate almost nothing, he stayed mostly alone, and in this state of grief he fell sick. We tried to help Flint in his sickness and misery. We took him food and stayed with him so that he would not feel utterly alone. But nothing helped, and about three weeks after Flo died, Flint died, too. It seems that because Flo had been too old to force the spoiled Flint to become independent, he simply couldn't face life without her."

Goodall (1996)

Descriptions reminiscent of such tragic depression and mourning are common, especially in dogs that have lost their human or animals that have lost their close mates. According to KüblerRoss's model of grief (Kübler-Ross and Kessler, 2007), the depression phase is followed by an acceptance phase that represents an understanding of the finality of death. In extended grief, as reflected in endless depression, the individual remains stuck in the depression phase or even regresses to preceding phases (e.g., denial) rather than progressing toward acceptance. Dying from depression without an understanding of the finality of death seems to reflect an unintentional death more than a rational act of suicide.

Altogether, the target article suggests a continuist approach that links human suicide with behaviors in animals that are reminiscent of what are considered a-posteriori as symptoms ("precursors") preceding suicide in humans. In the current absence of solid, reliable, and objective evidence, the continuist hypothesis does not present a step towards substantiating animal suicide as a scientific reality.

\section{References}

Goodall, J. (1996). My life with the chimpanzees. Aladdin Paperbacks, NY

King, B. J. (2013). How animals grieve. University of Chicago Press

King, B. J. (2016). Animal mourning: Précis of How animals grieve (King 2013). Animal Sentience 4(1)

Kübler-Ross, E., \& Kessler, D. (2007). On grief and grieving: Finding the meaning of grief through the five stages of loss. Scribner, NY

Monkey Commits Suicide. (1932, July 18). Barrier Miner (Broken Hill, NSW: 1888-1954), p. 3. Retrieved Jan. 9, 2018, from http://nla.gov.au/nla.news-article46659249

Peña-Guzmán, D. M. (2017). Can nonhuman animals commit suicide? Animal Sentience 20(1)

Randall, J. A., Hatch, S. M., \& Hekkala, E. R. (1995). Inter-specific variation in anti-predator behavior in sympatric species of kangaroo rat. Behavioral Ecology and Sociobiology, 36, 243-250

Suddendorf, T., \& Corballis, M. (2007). The evolution of foresight: What is mental time travel, and is it unique to humans? Behavioral and Brain Sciences, 30(3), 299-313 